\title{
Airway and ventilation management during cardiopulmonary resuscitation and after successful resuscitation
}

\author{
Christopher Newell, Scott Grier and Jasmeet Soar ${ }^{*}$ (D)
}

\begin{abstract}
After cardiac arrest a combination of basic and advanced airway and ventilation techniques are used during cardiopulmonary resuscitation (CPR) and after a return of spontaneous circulation (ROSC). The optimal combination of airway techniques, oxygenation and ventilation is uncertain. Current guidelines are based predominantly on evidence from observational studies and expert consensus; recent and ongoing randomised controlled trials should provide further information. This narrative review describes the current evidence, including the relative roles of basic and advanced (supraglottic airways and tracheal intubation) airways, oxygenation and ventilation targets during CPR and after ROSC in adults. Current evidence supports a stepwise approach to airway management based on patient factors, rescuer skills and the stage of resuscitation. During CPR, rescuers should provide the maximum feasible inspired oxygen and use waveform capnography once an advanced airway is in place. After ROSC, rescuers should titrate inspired oxygen and ventilation to achieve normal oxygen and carbon dioxide targets.
\end{abstract}

Keywords: Airway, Cardiac arrest, Cardiopulmonary resuscitation, Oxygenation, Ventilation

\section{Background}

Airway and ventilation interventions during cardiopulmonary resuscitation (CPR) and in those with a return of a spontaneous circulation (ROSC) follow a stepwise approach as the precise interventions are thought to depend on patient factors, rescuer skills and the stage of the resuscitation [1, 2]. Current guidelines for in-hospital cardiac arrest (IHCA) and out-of-hospital cardiac arrest (OHCA) are based primarily on evidence from observational studies and expert consensus, and the optimal interventions remain uncertain [3-5]. In addition, our knowledge of airway management during IHCA is mainly extrapolated from OHCA studies.

\section{Do we need an airway, oxygenation and ventilation during CPR?}

Current guidelines recommend that, after a primary cardiac arrest, restoring a circulation with chest compressions and, if appropriate, attempted defibrillation to restart the heart take priority over airway and ventilation interventions $[2$,

\footnotetext{
* Correspondence: jasmeetsoar@me.com

Intensive Care Unit, Southmead Hospital, North Bristol NHS Trust, Bristol BS10 $5 \mathrm{NB}$, UK
}

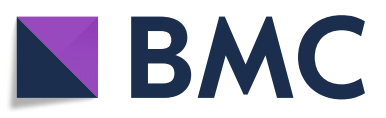

(c) The Author(s). 2018 Open Access This article is distributed under the terms of the Creative Commons Attribution 4.0 International License (http://creativecommons.org/licenses/by/4.0/), which permits unrestricted use, distribution, and reproduction in any medium, provided you give appropriate credit to the original author(s) and the source, provide a link to the Creative Commons license, and indicate if changes were made. The Creative Commons Public Domain Dedication waiver (http://creativecommons.org/publicdomain/zero/1.0/) applies to the data made available in this article, unless otherwise stated. voir at the time of cardiac arrest and further oxygen is only required after about 4 minutes. When cardiac arrest follows airway and/or breathing problems (asphyxial cardiac arrest), earlier interventions to restore adequate oxygenation to the vital organs may be preferable.

Current guidelines for CPR $[2-4,6]$ emphasise chest compressions for all cardiac arrests because:

- Chest compressions are easy to learn and do for most rescuers and do not require special equipment. Studies show that lay rescuer compression-only CPR is better than no CPR [7].

- Sudden cardiac arrest, with an initial shockable rhythm (ventricular fibrillation or pulseless ventricular tachycardia [VF/pVT]) has good outcomes with early CPR and early defibrillation [8].

- Survival after a non-cardiac cause of cardiac arrest, such as asphyxial cardiac arrest and which more commonly lead to an initial non-shockable cardiac arrest rhythm (pulseless electrical activity (PEA) or asystole), is relatively poor even if there is ROSC. Patients often have severe brain injury associated 
with hypoxaemia and low blood flow preceding cardiac arrest, a period of no or low flow during CPR and reperfusion injury following ROSC.

- As VF/pVT has a better response to treatment, CPR interventions prioritise treatment for $\mathrm{VF} / \mathrm{pVT}$ at the expense of those that may be helpful for PEA or asystole.

Observational data suggest that early lay-bystander compression-only CPR can improve survival after sudden cardiac arrest [9]. This could be because of an increased likelihood of bystanders performing compression-only CPR rather than no CPR, or CPR with long pauses for probably ineffective ventilation attempts. In addition, dispatch-assisted compression-only CPR appears to give similar or improved outcomes compared with dispatcher CPR instructions for both compressions and ventilations [5]. Additional benefits of CPR with compressions and ventilations are most likely when delivered by rescuers trained in ventilation, when emergency medical service (EMS) response times are long or after an asphyxial cardiac arrest $[2,6]$.

Some EMS services deliver continuous high-quality chest compressions with passive oxygenation with an oropharyngeal airway and simple oxygen mask (minimally interrupted cardiac resuscitation) and an advanced airway is delayed until after 600 chest compressions for witnessed OHCA with a shockable rhythm. Observational studies show improved survival to discharge for all adult OHCAs, and improved survival with good neurological outcome for witnessed cardiac arrest or if the initial rhythm is shockable [10]. Whether chest compressions generate a sufficient tidal volume for gas exchange is uncertain and likely to vary over time. Studies in late cardiac arrest (40-50 minutes) show that the tidal volumes generated are less than the patient's estimated deadspace [11].

\section{Steps for airway and ventilation management during CPR and after ROSC}

During CPR, airway interventions range from compression-only CPR with or without airway opening, mouth-to-mouth ventilation, mouth-to-mask ventilation, bag-mask ventilation (with or without an oropharyngeal airway) or advanced airways (supraglottic airways (SGAs) and tracheal intubation using direct or video laryngoscopy) (Fig. 1). In a feasibility study to inform a randomised controlled trial (RCT) of OHCA, patients in the 'usual' airway management group were observed to have both basic and advanced airway interventions which changed according to the skills of the rescuer present and the time-point during resuscitation [12].

After ROSC for both IHCA and OHCA, most patients have a post-cardiac arrest syndrome [13], are comatose with impaired airway reflexes and ventilation and/or have an indication for tracheal intubation based on their underlying condition $[14,15]$. Patients who remain conscious and do not require airway interventions tend to have an initial shockable rhythm, are treated early with defibrillation and have better outcomes. Tracheal intubation enables controlled ventilation to facilitate onwards transportation to the emergency department after OHCA, cardiac catheterisation laboratory or intensive care unit. Drug-assisted intubation by critical care teams for both IHCA and OHCA patients with ROSC using a protocol-based approach (e.g. with ketamine or midazolam, fentanyl and rocuronium) can be safe and effective $[16,17]$.

\section{Airway and ventilation techniques during CPR Bag-mask ventilation}

On arrival of trained rescuers, bag-mask ventilation with supplemental oxygen is the most common initial approach and can be aided with an oropharyngeal or nasopharyngeal airway. During CPR, the bag-mask is used to give two breaths after every 30 compressions. A large RCT of bag-mask ventilation without pausing compressions in OHCA found no difference in survival when compared with pausing for ventilation after every 30 compressions [18]. A pre-specified per-protocol analysis reported a significantly higher survival to discharge among those who actually received conventional CPR

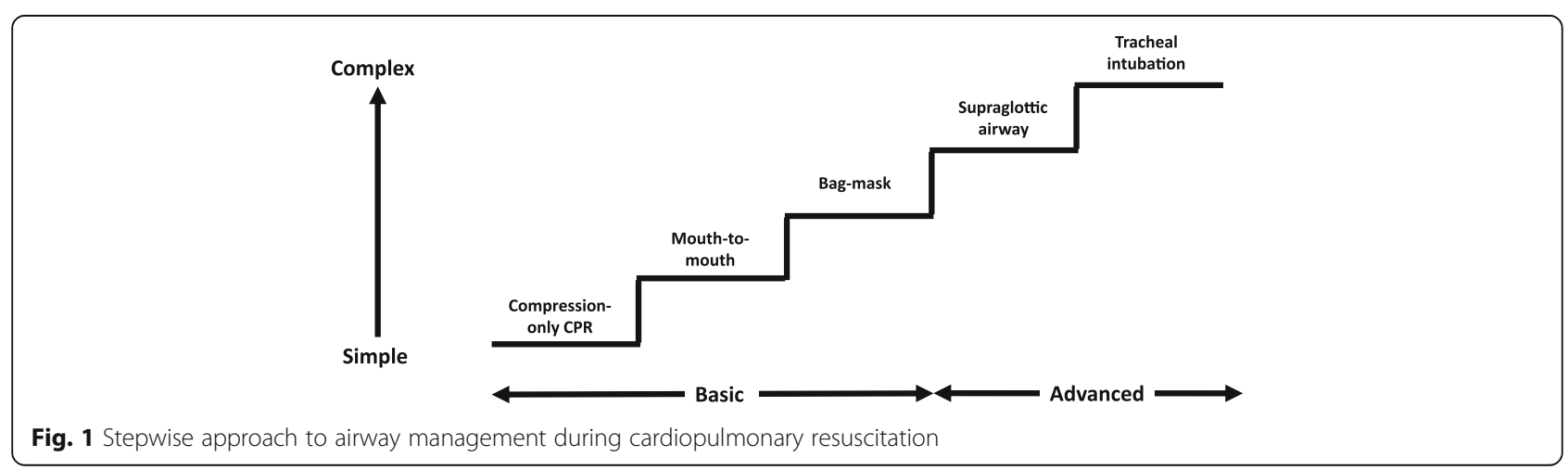


(30:2) compared with those who received continuous compressions.

\section{Supraglottic airways}

Supraglottic airway (SGA) use has increased during CPR as SGA insertion is easier to learn than tracheal intubation and feasible with fewer and shorter interruptions in chest compression [19]. Observational data show classic laryngeal airway mask (cLMA) use during CPR is associated with a lower incidence of regurgitation of gastric contents than bag-mask ventilation [20]. Second-generation SGAs (e.g. i-gel and LMA Supreme (LMAS)) have potential advantages over first-generation SGAs, including improved pharyngeal seal pressure, oesophageal drainage tubes and integrated bite blocks. A pig study raised concerns that a supraglottic cuff compresses the internal and external carotid artery, decreasing cerebral blood flow during CPR. A human radiographic study did not, however, observe any evidence of mechanical compression of the carotid arteries $[21,22]$.

\section{Tracheal intubation}

Tracheal intubation enables chest compressions to continue uninterrupted while the lungs are ventilated, avoids gastric insufflation and protects the lungs from aspiration of gastric contents: an observational study, however, showed one-third of OHCA patients had regurgitation, and in two-thirds this occurred before EMS arrival and in a quarter between EMS arrival and tracheal intubation [23]. Studies suggest more than 50 successful intubations are required to achieve an insertion success rates of over 90\% during CPR [24]. Current European guidelines recommend a pause in compressions of less than $5 \mathrm{~s}$ for tracheal tube insertion [1].

Videolaryngoscopy (VL) for tracheal intubation may have a role in tracheal intubation during CPR [25], although there are few studies of VL use during CPR. In one study of experienced clinicians, VL was associated with significantly fewer episodes of prolonged $(>10 \mathrm{~s}$ ) interruptions in chest compressions; the intubation success rate was not significantly different [26]. In a further study, VL use was associated with shorter pauses in compressions compared with direct laryngoscopy when initial tracheal intubation was not successful [27].

\section{Comparisons between airway techniques during CPR}

Comparisons between airway techniques are difficult as most patients have more than one airway technique during CPR [12], airway interventions depend on patient and event factors that are not reported (e.g. arrest location and access, obesity), rescuer ability determines technique success and
early-ROSC patients are less likely to need an advanced airway.

\section{Basic versus advanced airways during CPR}

Available evidence challenges the notion that 'advanced' (SGA or tracheal tube) interventions are better than 'basic' (bag-mask ventilation) interventions during CPR. Meta-analysis of observational studies of OHCA estimated an advanced airway was associated with a reduced survival to hospital discharge/30 days (odds ratio 0.49 (95\% confidence interval (CI) 0.37-0.65)) when compared with bag-mask ventilation [28]. Observational studies are likely to be confounded because, if ROSC occurs early, an advanced airway during CPR may not be required whereas patients with primary asphyxial cardiac arrest or aspiration of gastric contents tend to get an advanced airway and have a poorer outcome.

The Cardiac Arrest Airway Management (CAAM) multi-centre RCT randomised $2043 \mathrm{OHCA}$ patients to early tracheal intubation or bag-mask ventilation with delayed post-ROSC tracheal intubation, delivered by a physician-led prehospital care team [29]. Bag-mask compared to tracheal tube use failed to show non-inferiority or inferiority for favourable 28-day survival with neurological function (4.3 versus $4.2 \%$ ). The authors report this as an 'inconclusive result'. The bag-mask group had more airway complications: difficult airway management (18.1 vs $13.4 \%, P=0.004)$, failure (6.7 vs $2.1 \%, P<0.001$ ) and regurgitation of gastric contents $(15.2$ vs $7.5 \%$, $P<0.001)$. Oesophageal intubation was recognised and corrected in $10.2 \%$ of cases.

No large RCTs of airway management for IHCA have been conducted. Time-dependent propensity analysis of data from the American Heart Association Get With The Guidelines IHCA registry showed tracheal intubation during each of the first 15 minutes of resuscitation compared with no intubation during that minute was associated with decreased survival to hospital discharge [30]. This study using observational data could not correct for a number of confounders (e.g. skills and experience of rescuers, the cause of the cardiac arrest, CPR quality and the indication for intubation) and confounding by indication could influence the results. This study raises the possibility that early tracheal intubation could be harmful during CPR after IHCA and highlights the need for RCTs of IHCA airway management.

\section{Supraglottic airways versus tracheal intubation during CPR}

A meta-analysis of ten observational studies with 76,000 patients reported an association between tracheal intubation and an increased rate of neurologically intact survival (OR 1.33, CI 1.09-1.61) compared with SGA use [31]. A feasibility study of 615 OHCA patients to help 
inform a larger RCT randomised paramedics to use an i-gel, LMAS or usual care (most commonly tracheal intubation) [32]. This feasibility study, which is one of the largest RCTs of advanced airway management during CPR, found no difference in survival to discharge (i-gel 9.5\%, LMA supreme $6.9 \%$, usual care $8.6 \%$ ) or 90 days $(9.5 \%$ vs $6.9 \%$ ), neurocognitive function or quality of life between groups, but was not powered to detect clinically significant differences in these outcomes. Recruitment to the LMAS group was stopped because on three occasions rescuers were contaminated as chest compressions caused blood and vomit to be ejected forcefully from the LMAS gastric drainage port. First attempt placement success rates were $79 \%$ for the i-gel and $75 \%$ for the LMAS, and the first attempt tracheal intubation rate was $85 \%$. In an observational study of OHCA, successful placement of the laryngeal tube occurred in $85 \%$ of 344 patients [33].

A commonly cited reason against using a tracheal tube during CPR is that insertion leads to prolonged and potentially harmful interruptions in chest compression. In an observational study of 100 pre-hospital intubations by paramedics, tracheal intubation attempts during CPR caused a median $110 \mathrm{~s}$ (IQR 54-198 s) of interruption, and in a quarter of cases the interruptions were over $3 \mathrm{mi}-$ nutes [19]. More recent OHCA observational data (339 patients) suggest duration of the longest pauses, number of pauses over $10 \mathrm{~s}$ and chest compression fraction (proportion of time compressions being given) may be similar with bag-mask, SGA and tracheal intubation [27]. In addition, data from 2767 cases of OHCA suggest the chest compression fraction is only slightly less with a tracheal tube (72.4 vs 76.7\%) [34].

Finally, the Pragmatic Airway Resuscitation Trial (PART) cluster randomised trial comparing tracheal intubation with laryngeal tube (LT) insertion in 3005 OHCA patients has reported its initial results (presented at the Society for Academic Emergency Medicine, 16 May 2018) [35]. EMS were randomised in clusters with crossover at 3-5-month intervals. The primary end-point of 72-h survival was improved with LT compared with tracheal intubation (18.2 vs $15.3 \%$, adjusted difference $2.9 \%$ (95\% CI $0.2-5.6 \%), P<0.01)$, as were the secondary outcomes of ROSC (27.9 vs $24.1 \%, P=0.02)$, hospital survival (10.8 vs $8.0 \%, P=0.01)$ and favourable neurological status at discharge ( 7.0 vs $5.0 \%, P=0.02)$. The full results of PART and another large RCT that compares i-gel with tracheal intubation during OHCA are awaited [36].

\section{The role of waveform capnography during CPR and after ROSC}

Waveform capnography is recommended whenever an advanced airway (SGA or tracheal tube) is used both during CPR and after ROSC [1]. A SGA will provide reliable end-tidal carbon dioxide values $\left(\mathrm{ETCO}_{2}\right)$ when there is a good seal. The $\mathrm{ETCO}_{2}$ depends on a large number of physiological variables (including cardiac output, metabolic state, lung function). This will lead to some limitations in the usefulness of $\mathrm{ETCO}_{2}$ monitoring during CPR and after ROSC. Waveform capnography has the following roles during $\mathrm{CPR}$ :

1. Confirms correct tracheal tube placement [4].

2. Helps guide rescuers to ventilate at the correct rate, although chest compression artefacts may lead to a falsely high ventilation rate [37].

3. Helps guide chest compression quality. A recent study suggests an association between high-quality chest compressions with a higher $\mathrm{ETCO}_{2}$ and defibrillation success after OHCA [38].

4. Helps identify ROSC during CPR. An increase in $\mathrm{ETCO}_{2}$ during CPR or a rising trend may indicate ROSC [39].

5. Helps make decisions about stopping CPR. A systematic review of 17 observational studies observed an association between a low $\mathrm{ETCO}_{2}(<$ $10 \mathrm{mmHg}$ at 20 minutes) with a low likelihood of ROSC $(<0.5 \%)$ [40]. Given the large number of factors that can influence the $\mathrm{ETCO}_{2}$, trends in $\mathrm{ETCO}_{2}$ during $\mathrm{CPR}$ rather than single values may be more important to guide decisions. In addition, a multi-modal approach rather than the $\mathrm{ETCO}_{2}$ alone should be used in prognostic decisions during CPR.

Waveform capnography helps guide ventilation rate and correct tracheal tube placement after ROSC. Post-ROSC patients often have a poor cardiac output and a large alveolar deadspace and this effects the correlation between $\mathrm{ETCO}_{2}$ and arterial partial pressure of carbon oxygen $\left(\mathrm{PaCO}_{2}\right)$. In an arterial blood gas study, the median (interquartile range) $\mathrm{PaCO}_{2}$ was 67 (34) mmHg and $\mathrm{ETCO}_{2} 31$ (25) $\mathrm{mmHg}$ during CPR, and after ROSC the $\mathrm{PaCO}_{2}$ was 58 (21) $\mathrm{mmHg}$ and $\mathrm{ETCO}_{2} 37.5$ (17) $\mathrm{mmHg}$ [41]. Data from the TTM study show patients managed at $33^{\circ} \mathrm{C}$ have a lower $\mathrm{ETCO}_{2}$ than those at $36^{\circ} \mathrm{C}$. Observational studies show an increased $\mathrm{PaCO}_{2}$ to $\mathrm{ETCO}_{2}$ gap both during CPR and after ROSC is associated with decreased ROSC and survival to hospital discharge, respectively $[41,42]$.

\section{How much oxygen during CPR and after ROSC?}

The optimal oxygen requirement for $\mathrm{CPR}$ and after ROSC remains uncertain [43] - too little is harmful, too much could be harmful, and what's just right and how it should be measured and targeted are uncertain.

Current guidelines recommend giving the maximum feasible inspired oxygen during CPR based on the premise that restoring depleted oxygen levels and correcting tissue hypoxia improves survival. Observational data show an association between higher arterial oxygen partial pressures 
during CPR and improved ROSC $[1,4,41,44]$. Due to the low flow cardiac output state, despite administration of a high inspired fraction of oxygen, target tissue mitochondrial oxygen tension is unlikely to be high [45].

After ROSC, the inspired oxygen should be titrated to achieve normal oxygen saturations (94-98\%) once oxygenation can be reliably monitored with pulse oximetry $[4,46]$. Observational studies show that hypoxia after ROSC is associated with a decrease in survival to hospital discharge [47-49]. The effect of hyperoxia after ROSC is less certain. Post-cardiac arrest syndrome includes reperfusion injury and oxidative stress, which can lead to neuronal damage. Hyperoxia is thought to further increase oxidative stress [45]. Animal studies show that hyperoxia immediately after ROSC is associated with a worse neurological outcome [50]. A small RCT of 28 OHCA patients showed a greater rise in neuron-specific enolase (NSE), a serum marker for neuronal injury, in post-ROSC patients treated with $100 \%$ inspired oxygen compared with $30 \%$ inspired oxygen for 60 minutes after ROSC (neither group received any temperature control) [51]. Several studies show an association between hyperoxia and worse outcome at hospital discharge (overall survival, or survival with good neurological function) when compared with normoxia, while others report no association [4, 47, 49, 52-57]. These studies are difficult to interpret as a high inspired oxygen may be a surrogate marker of illness severity, the studies have not looked at oxygenation immediately after ROSC (the time period where animal studies show harm), the actual duration ('dose') of hyperoxia for an individual patient is unknown and the impact of other interventions (e.g. temperature control, carbon dioxide target) is uncertain. A feasibility study of titrated oxygen immediately after ROSC struggled to reliably measure oxygen saturation to enable titration of inspired oxygen using a bag-mask [58]. An RCT of titrating oxygen immediately after ROSC is about to start (Table 1).

\section{How much ventilation during CPR and after ROSC?}

In the absence of an advanced airway during CPR, current guidelines based on very limited evidence recommend two positive pressure breaths after every 30 chest compressions. These breaths should be of an inspiratory time of $1 \mathrm{~s}$ and produce a visible chest wall rise [59]. Observations in anesthetised adults show a visible chest rise occurs with a mean tidal volume of $384 \mathrm{ml}$ (95\% CI 362 to $406 \mathrm{ml}$ [ [60]. Once an advanced airway is in place, a ventilation rate of $10 \mathrm{~min}^{-1}$ without interrupting chest compressions is recommended. Continuous uninterrupted chest compressions are not always feasible with a SGA and there may be a need to pause after every 30 chest compressions in order to give two rescue breaths.
Our understanding of the optimal ventilation strategy and its interaction with chest compressions to generate adequate blood flow and oxygen delivery to vital organs is limited [61]. The recommended ventilation rate of $10 \mathrm{~min}^{-1}$ with a tracheal tube is based predominantly on animal studies, which followed observations that hyperventilation was common during human CPR [62]. A pig study showed a respiratory rate of $30 \mathrm{~min}^{-1} \mathrm{com}$ pared to $12 \mathrm{~min}^{-1}$ caused increased intrathoracic pressure, a decrease in coronary and cerebral perfusion and decreased ROSC [63, 64]. Furthermore, the authors included human observational data and reported no survivors from cardiac arrest with an advanced airway when the respiratory rate was greater than $10 \mathrm{~min}^{-1}$ and the inspiratory time greater than $1 \mathrm{~s}$. A reduced ventilation rate may be sufficient to maintain a normal ventilation perfusion ratio during CPR as the cardiac output generated by chest compressions is also markedly reduced.

The interaction between the lungs and circulation during CPR are complex [61]. Increasing ventilation rate or tidal volume during CPR increases the mean intrathoracic pressure and reduces venous return to the heart, increases lung volume and pulmonary vascular resistance, reduces cardiac output and decreases coronary perfusion pressure and aortic blood pressure. Devices designed to regulate intrathoracic pressure such as the impedance threshold device (ITD) and active compression decompression CPR devices (ACD CPR) aim to augment blood flow to the heart and brain during CPR. Specifically, the ITD stops airflow into the lungs during chest compression recoil or active decompression and the negative resultant intrathoracic pressure increases blood flow into the ventricles. Compared with standard CPR, ITD CPR and ACD + ITD CPR augment cardiac output for the next compression [61]. Despite the promising effects of ITD + ACD CPR in animal models, the results from human trials are less convincing. Studies of the ITD alone show no improvement in survival. The International Liaison Committee on Resuscitation (ILCOR) 2015 review of the science of ACD + ITD CPR did not achieve consensus regarding its use, albeit a large RCT had reported improved survival with good neurological function [4].

Current guidelines for post-ROSC care recommend using low tidal volume ventilation $\left(6-8 \mathrm{ml} \mathrm{kg}^{-1}\right.$ IBW) with titrated levels of PEEP and aiming for normocapnia [46]. After ROSC, inadequate ventilation and resultant hypercapnia will exacerbate any existing metabolic acidosis and potentially worsen any haemodynamic instability. In addition, hypercapnia produces cerebral vasodilatation if cerebrovascular reactivity is preserved: whether this is detrimental or beneficial is not known. Hypercapnia may lead to an elevation in intracranial pressure and worsening of hyperaemia in a vulnerable 


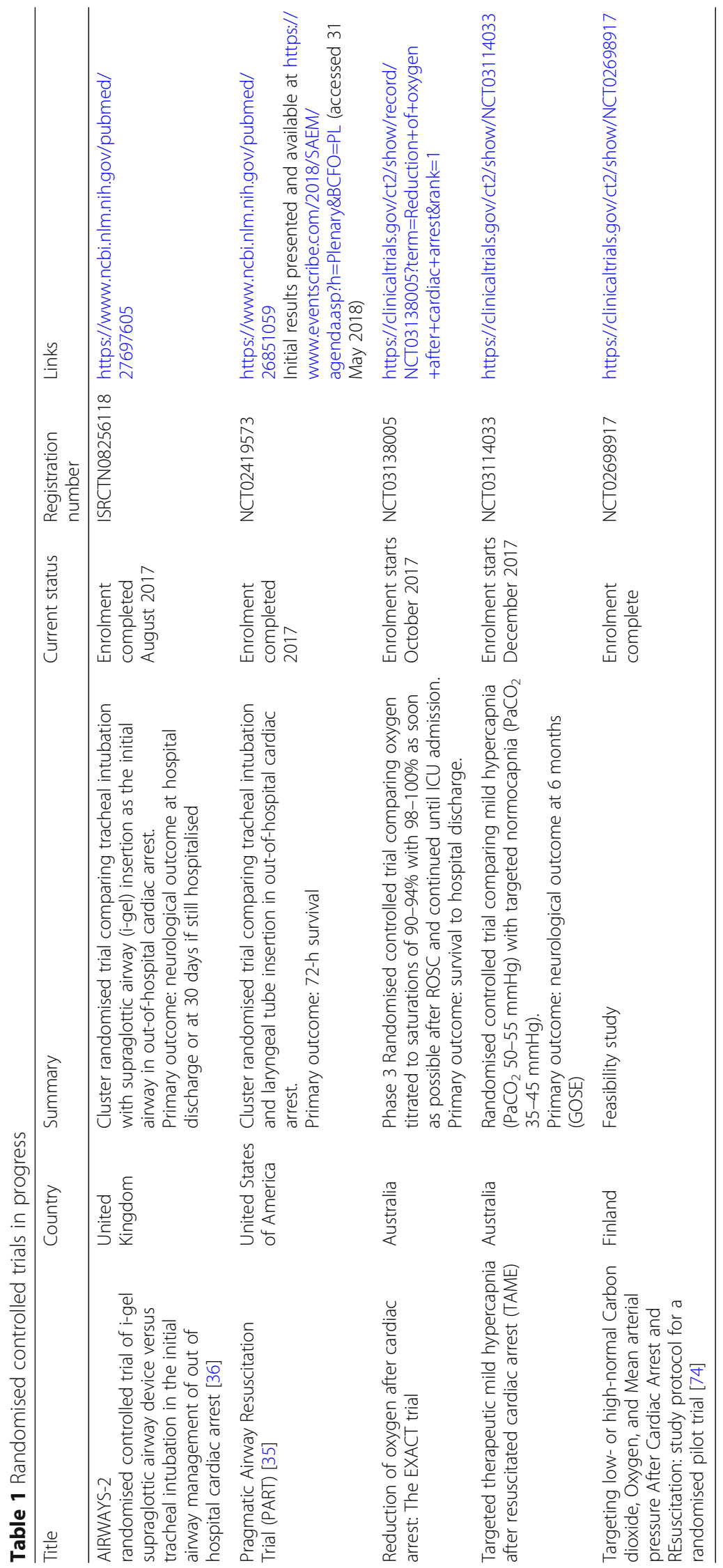


brain, or increased blood flow may improve cerebral ischaemia and be neuroprotective. One observational study showed improved survival to hospital discharge and neurological outcomes associated with exposure to mild hypercapnia compared to normocapnia or hypocapnia [65], whereas another showed worse survival to discharge with hypercapnia compared to normocapnia or hypocapnia [49]. In a small RCT of 86 post-cardiac arrest patients there was a greater increase in NSE (a marker of neuronal injury) in the first $72 \mathrm{~h}$ when normocapnia $(35-45 \mathrm{mmHg}$, $4.67-6.0 \mathrm{kPa}$ ) was targeted compared to mild hypercapnia (50-55 mmHg, 6.67-7.33 kPa) [66]. This study is being followed up with a larger multi-centre RCT (The TAME Cardiac Arrest trial). Hyperventilation and hypocapnia may also cause cerebral ischaemia as a result of cerebral vasoconstriction, cerebrospinal fluid alkalosis and increased neuronal excitability due to increased excitatory amino acid release [67]. A ten-patient study showed decreased cerebral tissue oxygenation monitored by near infrared spectroscopy when the target $\mathrm{PaCO}_{2}$ decreased from $40(5.33 \mathrm{kPa})$ to $30 \mathrm{mmHg}(4.0 \mathrm{kPa})$ in post-ROSC patients treated with hypothermia [68]. A study of 5258 patients (82 ICUs in the Netherlands) observed a risk-adjusted increased mortality with hypocapnia compared with normocapnia and hypercapnia [69].

A post-ROSC lung protective ventilation strategy is based on guidance for acute lung injury ventilation. One study comparing a tidal volume less than or greater than $8 \mathrm{ml} \mathrm{kg}{ }^{-1}$ in OHCA survivors observed a lower tidal volume in the first $48 \mathrm{~h}$ post-ROSC was associated with a favourable neurocognitive outcome, more ventilator and shock-free days [70], whereas an IHCA study found no association between a tidal volume of less or greater than $8 \mathrm{ml} \mathrm{kg}^{-1}$ in the first 6 or $48 \mathrm{~h}$ post-ROSC and survival to discharge and neurological outcome [71]. In the TTM trial, the end of TTM median tidal volume was $7.7 \mathrm{ml} \mathrm{kg}{ }^{-1}$ predicted body weight, $60 \%$ of patients had a tidal volume less than $8 \mathrm{ml} \mathrm{kg}^{-1}$, median PEEP was 7.7 $\mathrm{cmH}_{2} \mathrm{O}$ (6.4-8.7), mean driving pressure was 14.6 $\mathrm{cmH}_{2} \mathrm{O}( \pm 4.3)$ and median $\mathrm{FiO}_{2}$ was $0.35(0.30-0.45)$ [72]. Non-survivors compared with survivors at 28 days had worse oxygenation, higher respiratory rates, driving pressures and plateau pressures and lower compliance compared to survivors.

After ROSC, interventions for oxygenation and ventilation in combination with a bundle of interventions that adjust other physiological variables, including temperature, blood pressure, glucose and seizure control, are probably required for a good outcome [73]. The optimal targets and combinations are uncertain and the subject of ongoing studies [74].

\section{Randomised controlled trials in progress}

There is clinical equipoise regarding the optimal airway, ventilation and oxygenation strategy during $C P R$ and after ROSC. Several RCTs are currently in progress and these studies are summarised in Table 1.

\section{Conclusions}

The optimal combination of airway techniques and oxygen and ventilation targets during CPR and after ROSC is uncertain. In the absence of evidence to favour a specific technique, rescuers should use the airway technique they are most proficient in during CPR and give the maximum feasible inspired oxygen concentration. Patients usually receive a stepwise approach as expert help arrives (Fig. 1). A compression to ventilation ratio of 30:2 should be used until an advanced airway is inserted, when a ventilation rate of $10 \mathrm{~min}^{-1}$ should be used without interrupting chest compressions. After ROSC, oxygenation and ventilation should be titrated to achieve normal values. Ongoing RCTs (Table 1) should provide new insights.

\section{Abbreviations \\ ACD: Active compression-decompression; $\mathrm{CO}_{2}$ : Carbon dioxide; CPR: Cardiopulmonary resuscitation; DL: Direct laryngoscopy; \\ EMS: Emergency medical service; $\mathrm{ETCO}_{2}$ : End-tidal carbon dioxide; $\mathrm{FiO}_{2}$ : Fraction inspired oxygen; IBW: Ideal body weight; IHCA: In-hospital cardiac arrest; IQR: Inter-quartile range; ITD: Impedance threshold valve; NSE: Neuron specific enolase; OHCA: Out-of-hospital cardiac arrest; $\mathrm{PaCO}_{2}$ : Partial pressure of arterial carbon dioxide; PEEP: Positive end expiratory pressure; RCT: Randomised controlled trial; ROSC: Return of spontaneous circulation; SGA: Supraglottic airway; TTM: Targeted temperature management; VF/pVT: Ventricular fibrillation/pulseless ventricular tachycardia; VL: Videolaryngoscopy}

\section{Authors' contributions}

All the authors were responsible for conception and design, data interpretation, manuscript writing, revision and final approval of the manuscript.

\section{Ethics approval and consent to participate}

Not applicable.

Consent for publication

Not applicable.

\section{Competing interests}

CN and SG declare no conflicts of interest. JS is a paid Editor for the journal Resuscitation, Chair of the Advanced Life Support Task Force of the International Liaison Committee on Resuscitation (ILCOR) and a steering group member for the AIRWAYS-2 Study.

\section{Publisher's Note}

Springer Nature remains neutral with regard to jurisdictional claims in published maps and institutional affiliations.

Received: 9 January 2018 Accepted: 4 July 2018

Published online: 15 August 2018

\section{References}

1. Soar J, Nolan JP, Bottiger BW, Perkins GD, Lott C, Carli P, Pellis T, Sandroni C, Skrifvars MB, Smith GB, et al. European Resuscitation Council Guidelines for Resuscitation 2015: Section 3. Adult advanced life support. Resuscitation. 2015:95:100-47.

2. Perkins GD, Olasveengen TM, Maconochie I, Soar J, Wyllie J, Greif R, Lockey A, Semeraro F, Van de Voorde P, Lott C, et al. European resuscitation council guidelines for resuscitation: 2017 update. Resuscitation. 2017;123:43-50. 
3. Perkins GD, Travers AH, Berg RA, Castren M, Considine J, Escalante R, Gazmuri RJ, Koster RW, Lim SH, Nation KJ, et al. Part 3: adult basic life support and automated external defibrillation: 2015 international consensus on cardiopulmonary resuscitation and emergency cardiovascular care science with treatment recommendations. Resuscitation. 2015;95:e43-69.

4. Soar J, Callaway CW, Aibiki M, Bottiger BW, Brooks SC, Deakin CD, Donnino MW, Drajer S, Kloeck W, Morley PT, et al. Part 4: advanced life support: 2015 international consensus on cardiopulmonary resuscitation and emergency cardiovascular care science with treatment recommendations. Resuscitation. 2015;95:e71-120.

5. Olasveengen TM, de Caen AR, Mancini ME, Maconochie IK, Aickin R, Atkins DL, Berg RA, Bingham RM, Brooks SC, Castren M, et al. 2017 International consensus on cardiopulmonary resuscitation and emergency cardiovascular care science with treatment recommendations summary. Resuscitation. 2017:121:201-14.

6. Kleinman ME, Goldberger ZD, Rea T, Swor RA, Bobrow BJ, Brennan EE, Terry M, Hemphill R, Gazmuri RJ, Hazinski MF, et al. 2017 American Heart Association focused update on adult basic life support and cardiopulmonary resuscitation quality: an update to the American Heart Association guidelines for cardiopulmonary resuscitation and emergency cardiovascular care. Circulation. 2018;137(1):e7-e13.

7. Ashoor HM, Lillie E, Zarin W, Pham B, Khan PA, Nincic V, Yazdi F, Ghassemi M, Ivory J, Cardoso R, et al. Effectiveness of different compression-toventilation methods for cardiopulmonary resuscitation: a systematic review. Resuscitation. 2017;118:112-25.

8. Hawkes C, Booth S, Ji C, Brace-McDonnell SJ, Whittington A, Mapstone J, Cooke MW, Deakin CD, Gale CP, Fothergill R, et al. Epidemiology and outcomes from out-of-hospital cardiac arrests in England. Resuscitation. 2017;110:133-40.

9. Iwami T, Kitamura T, Kiyohara K, Kawamura T. Dissemination of chest compression-only cardiopulmonary resuscitation and survival after out-ofhospital cardiac arrest. Circulation. 2015;132(5):415-22.

10. Kleinman ME, Brennan EE, Goldberger ZD, Swor RA, Terry M, Bobrow BJ, Gazmuri RJ, Travers AH, Rea T. Part 5: adult basic life support and cardiopulmonary resuscitation quality: 2015 American Heart Association guidelines update for cardiopulmonary resuscitation and emergency cardiovascular care. Circulation. 2015;132(18 Suppl 2):S414-35.

11. Deakin CD, O'Neill JF, Tabor T. Does compression-only cardiopulmonary resuscitation generate adequate passive ventilation during cardiac arrest? Resuscitation. 2007;75(1):53-9.

12. Voss S, Rhys M, Coates D, Greenwood R, Nolan JP, Thomas M, Benger J. How do paramedics manage the airway during out of hospital cardiac arrest? Resuscitation. 2014;85(12):1662-6.

13. Nolan JP, Neumar RW, Adrie C, Aibiki M, Berg RA, Bottiger BW, Callaway C, Clark RS, Geocadin RG, Jauch EC, et al. Post-cardiac arrest syndrome: epidemiology, pathophysiology, treatment, and prognostication. A scientific statement from the international liaison committee on resuscitation; the American Heart Association emergency cardiovascular care committee; the council on cardiovascular surgery and anesthesia; the council on cardiopulmonary, perioperative, and critical care; the council on clinical cardiology; the council on stroke. Resuscitation. 2008;79(3):350-79.

14. Deakin CD, Fothergill R, Moore F, Watson L, Whitbread M. Level of consciousness on admission to a heart attack Centre is a predictor of survival from out-of-hospital cardiac arrest. Resuscitation. 2014;85(7):905-9.

15. Berg KM, Grossestreuer AV, Uber A, Patel PV, Donnino MW. Intubation is not a marker for coma after in-hospital cardiac arrest: a retrospective study. Resuscitation. 2017;119:18-20.

16. Miller M, Groombridge CJ, Lyon R. Haemodynamic changes to a midazolamfentanyl-rocuronium protocol for pre-hospital anaesthesia following return of spontaneous circulation after cardiac arrest. Anaesthesia. 2017;72(5):585-91.

17. Miller M, Kruit N, Heldreich C, Ware S, Habig K, Reid C, Burns B. Hemodynamic response after rapid sequence induction with ketamine in out-of-hospital patients at risk of shock as defined by the shock index. Ann Emerg Med. 2016;68(2):181-8. e182

18. Nichol G, Leroux B, Wang H, Callaway CW, Sopko G, Weisfeldt M, Stiell I, Morrison LJ, Aufderheide TP, Cheskes S, et al. Trial of continuous or interrupted chest compressions during CPR. N Engl J Med. 2015;373(23): 2203-14.

19. Wang HE, Simeone SJ, Weaver MD, Callaway CW. Interruptions in cardiopulmonary resuscitation from paramedic endotracheal intubation. Ann Emerg Med. 2009;54(5):645-52. e641
20. Stone BJ, Chantler PJ, Baskett PJ. The incidence of regurgitation during cardiopulmonary resuscitation: a comparison between the bag valve mask and laryngeal mask airway. Resuscitation. 1998;38(1):3-6.

21. Segal N, Yannopoulos D, Mahoney BD, Frascone RJ, Matsuura T, Cowles CG, McKnite SH, Chase DG. Impairment of carotid artery blood flow by supraglottic airway use in a swine model of cardiac arrest. Resuscitation. 2012;83(8):1025-30.

22. White JM, Braude DA, Lorenzo G, Hart BL. Radiographic evaluation of carotid artery compression in patients with extraglottic airway devices in place. Acad Emerg Med. 2015;22(5):636-8.

23. Simons RW, Rea TD, Becker LJ, Eisenberg MS. The incidence and significance of emesis associated with out-of-hospital cardiac arrest. Resuscitation. 2007;74(3):427-31.

24. Buis ML, Maissan IM, Hoeks SE, Klimek M, Stolker RJ. Defining the learning curve for endotracheal intubation using direct laryngoscopy: a systematic review. Resuscitation. 2016:99:63-71.

25. Arulkumaran N, Lowe J, lons R, Mendoza M, Bennett V, Dunser MW. Videolaryngoscopy versus direct laryngoscopy for emergency orotracheal intubation outside the operating room: a systematic review and metaanalysis. Br J Anaesth. 2018;120(4):712-24.

26. Kim JW, Park SO, Lee KR, Hong DY, Baek KJ, Lee YH, Lee JH, Choi PC. Video laryngoscopy vs. direct laryngoscopy: which should be chosen for endotracheal intubation during cardiopulmonary resuscitation? A prospective randomized controlled study of experienced intubators. Resuscitation. 2016;105:196-202.

27. Jarman AF, Hopkins CL, Hansen JN, Brown JR, Burk C, Youngquist ST. Advanced airway type and its association with chest compression interruptions during out-of-hospital cardiac arrest resuscitation attempts. Prehosp Emerg Care. 2017;21(5):628-35.

28. Fouche PF, Simpson PM, Bendall J, Thomas RE, Cone DC, Doi SA. Airways in out-of-hospital cardiac arrest: systematic review and meta-analysis. Prehosp Emerg Care. 2014;18(2):244-56.

29. Jabre P, Penaloza A, Pinero D, Duchateau FX, Borron SW, Javaudin F, Richard $\mathrm{O}$, de Longueville $\mathrm{D}$, Bouilleau G, Devaud ML, et al. Effect of bag-mask ventilation vs endotracheal intubation during cardiopulmonary resuscitation on neurological outcome after out-of-hospital cardiorespiratory arrest: a randomized clinical trial. JAMA. 2018;319(8):779-87.

30. Andersen LW, Granfeldt A, Callaway CW, Bradley SM, Soar J, Nolan JP, Kurth T, Donnino MW, American Heart Association's get with the GuidelinesResuscitation I. Association between tracheal intubation during adult inhospital cardiac arrest and survival. JAMA. 2017;317(5):494-506.

31. Benoit JL, Gerecht RB, Steuerwald MT, McMullan JT. Endotracheal intubation versus supraglottic airway placement in out-of-hospital cardiac arrest: a meta-analysis. Resuscitation. 2015;93:20-6.

32. Benger J, Coates D, Davies S, Greenwood R, Nolan J, Rhys M, Thomas M, Voss S. Randomised comparison of the effectiveness of the laryngeal mask airway supreme, i-gel and current practice in the initial airway management of out of hospital cardiac arrest: a feasibility study. Br J Anaesth. 2016;116(2):262-8.

33. Vithalani VD, VIk S, Davis SQ, Richmond NJ. Unrecognized failed airway management using a supraglottic airway device. Resuscitation. 2017;119:1-4.

34. Kurz MC, Prince DK, Christenson J, Carlson J, Stub D, Cheskes S, Lin S, Aziz M, Austin M, Vaillancourt C, et al. Association of advanced airway device with chest compression fraction during out-of-hospital cardiopulmonary arrest. Resuscitation. 2016;98:35-40.

35. Wang HE, Prince DK, Stephens SW, Herren H, Daya M, Richmond N, Carlson J, Warden C, Colella MR, Brienza A, et al. Design and implementation of the resuscitation outcomes consortium pragmatic airway resuscitation trial (PART). Resuscitation. 2016;101:57-64.

36. Taylor J, Black S, S JB, Kirby K, Nolan JP, Reeves BC, Robinson M, Rogers CA, Scott LJ, South A, et al. Design and implementation of the AIRWAYS-2 trial: a multi-Centre cluster randomised controlled trial of the clinical and cost effectiveness of the i-gel supraglottic airway device versus tracheal intubation in the initial airway management of out of hospital cardiac arrest. Resuscitation. 2016;109:25-32.

37. Leturiondo M, de Gauna SR, Ruiz JM, Gutierrez JJ, Leturiondo LA, GonzalezOtero DM, Russell JK, Zive D, Daya M. Influence of chest compression artefact on capnogram-based ventilation detection during out-of-hospital cardiopulmonary resuscitation. Resuscitation. 2017;

38. Savastano S, Baldi E, Raimondi M, Palo A, Belliato M, Cacciatore E, Corazza V, Molinari S, Canevari F, Danza Al, et al. End-tidal carbon dioxide and defibrillation success in out-of-hospital cardiac arrest. Resuscitation. 2017;121:71-5. 
39. Venkatesh $\mathrm{H}$, Keating E. BET 1: can the value of end tidal $\mathrm{CO} 2$ prognosticate ROSC in patients coming into emergency department with an out-ofhospital cardiac arrest (OOHCA)? Emerg Med J. 2017;34(3):187-9.

40. Paiva EF, Paxton JH, O'Neil BJ. The use of end-tidal carbon dioxide (ETCO2) measurement to guide management of cardiac arrest: a systematic review. Resuscitation. 2017:123:1-7.

41. Spindelboeck W, Gemes G, Strasser C, Toescher K, Kores B, Metnitz P, Haas J, Prause $G$. Arterial blood gases during and their dynamic changes after cardiopulmonary resuscitation: a prospective clinical study. Resuscitation. 2016; 106:24-9.

42. Kim YW, Hwang SO, Kang HS, Cha KC. The gradient between arterial and end-tidal carbon dioxide predicts in-hospital mortality in post-cardiac arrest patient. Am J Emerg Med. 2018. https://doi.org/10.1016/j.ajem.2018.04.025. [Epub ahead of print]

43. O'Driscoll BR, Howard LS, Earis J, Mak V, British Thoracic Society Emergency Oxygen Guideline G, Group BTSEOGD. BTS guideline for oxygen use in adults in healthcare and emergency settings. Thorax. 2017;72(Suppl 1):ii1-ii90.

44. Spindelboeck W, Schindler O, Moser A, Hausler F, Wallner S, Strasser C, Haas J, Gemes G, Prause G. Increasing arterial oxygen partial pressure during cardiopulmonary resuscitation is associated with improved rates of hospital admission. Resuscitation. 2013;84(6):770-5.

45. Neumar RW. Optimal oxygenation during and after cardiopulmonary resuscitation. Curr Opin Crit Care. 2011;17(3):236-40.

46. Nolan JP, Soar J, Cariou A, Cronberg T, Moulaert VR, Deakin CD, Bottiger BW, Friberg $\mathrm{H}$, Sunde $\mathrm{K}$, Sandroni C. European resuscitation council and European Society of Intensive Care Medicine Guidelines for postresuscitation care 2015: Section 5 of the European Resuscitation Council Guidelines for Resuscitation 2015. Resuscitation. 2015;95:202-22.

47. Kilgannon JH, Jones AE, Shapiro NI, Angelos MG, Milcarek B, Hunter K, Parrillo JE, Trzeciak S, Emergency Medicine Shock Research Network I. Association between arterial hyperoxia following resuscitation from cardiac arrest and in-hospital mortality. JAMA. 2010;303(21):2165-71.

48. Bellomo R, Bailey M, Eastwood GM, Nichol A, Pilcher D, Hart GK, Reade MC, Egi M, Cooper DJ, Study of Oxygen in Critical Care G. Arterial hyperoxia and inhospital mortality after resuscitation from cardiac arrest. Crit Care. 2011;15(2):R90.

49. Wang HE, Prince DK, Drennan IR, Grunau B, Carlbom DJ, Johnson N, Hansen M, Elmer J, Christenson J, Kudenchuk P, et al. Post-resuscitation arterial oxygen and carbon dioxide and outcomes after out-of-hospital cardiac arrest. Resuscitation. 2017;120:113-8.

50. Pilcher J, Weatherall M, Shirtcliffe P, Bellomo R, Young P, Beasley R. The effect of hyperoxia following cardiac arrest - a systematic review and metaanalysis of animal trials. Resuscitation. 2012;83(4):417-22.

51. Kuisma M, Boyd J, Voipio V, Alaspaa A, Roine RO, Rosenberg P. Comparison of 30 and the $100 \%$ inspired oxygen concentrations during early postresuscitation period: a randomised controlled pilot study. Resuscitation. 2006;69(2):199-206.

52. Janz DR, Hollenbeck RD, Pollock JS, McPherson JA, Rice TW. Hyperoxia is associated with increased mortality in patients treated with mild therapeutic hypothermia after sudden cardiac arrest. Crit Care Med. 2012; 40(12):3135-9.

53. Kilgannon JH, Jones AE, Parrillo JE, Dellinger RP, Milcarek B, Hunter K, Shapiro NI, Trzeciak S, Emergency Medicine Shock Research Network I. Relationship between supranormal oxygen tension and outcome after resuscitation from cardiac arrest. Circulation. 2011;123(23):2717-22.

54. Elmer J, Scutella M, Pullalarevu R, Wang B, Vaghasia N, Trzeciak S, RosarioRivera BL, Guyette FX, Rittenberger JC, Dezfulian C, et al. The association between hyperoxia and patient outcomes after cardiac arrest: analysis of a high-resolution database. Intensive Care Med. 2015;41(1):49-57.

55. Nelskyla A, Parr MJ, Skrifvars MB. Prevalence and factors correlating with hyperoxia exposure following cardiac arrest--an observational single centre study. Scand J Trauma Resusc Emerg Med. 2013;21:35.

56. Ihle JF, Bernard S, Bailey MJ, Pilcher DV, Smith K, Scheinkestel CD. Hyperoxia in the intensive care unit and outcome after out-of-hospital ventricular fibrillation cardiac arrest. Crit Care Resusc. 2013;15(3):186-90.

57. Vaahersalo J, Bendel S, Reinikainen M, Kurola J, Tiainen M, Raj R, Pettila V, Varpula T, Skrifvars MB, Group FS. Arterial blood gas tensions after resuscitation from out-of-hospital cardiac arrest: associations with long-term neurologic outcome. Crit Care Med. 2014;42(6):1463-70.

58. Young P, Bailey M, Bellomo R, Bernard S, Dicker B, Freebairn R, Henderson S, Mackle D, McArthur C, McGuinness S, et al. HyperOxic therapy OR NormOxic therapy after out-of-hospital cardiac arrest (HOT OR NOT): a randomised controlled feasibility trial. Resuscitation. 2014;85(12):1686-91.

59. Perkins GD, Handley AJ, Koster RW, Castren M, Smyth MA, Olasveengen T, Monsieurs KG, Raffay V, Grasner JT, Wenzel V, et al. European Resuscitation Council Guidelines for Resuscitation 2015: Section 2. Adult basic life support and automated external defibrillation. Resuscitation. 2015:95:81-99.

60. Baskett P, Nolan J, Parr M. Tidal volumes which are perceived to be adequate for resuscitation. Resuscitation. 1996;31(3):231-4.

61. Lurie KG, Nemergut EC, Yannopoulos D, Sweeney M. The physiology of cardiopulmonary resuscitation. Anesth Analg. 2016;122(3):767-83.

62. Vissers G, Soar J, Monsieurs KG. Ventilation rate in adults with a tracheal tube during cardiopulmonary resuscitation: a systematic review. Resuscitation. 2017;119:5-12.

63. Aufderheide TP, Sigurdsson G, Pirrallo RG, Yannopoulos D, McKnite S, von Briesen C, Sparks CW, Conrad CJ, Provo TA, Lurie KG. Hyperventilationinduced hypotension during cardiopulmonary resuscitation. Circulation. 2004;109(16):1960-5.

64. Aufderheide TP, Lurie KG. Death by hyperventilation: a common and lifethreatening problem during cardiopulmonary resuscitation. Crit Care Med. 2004;32(9 Suppl):S345-51.

65. Schneider AG, Eastwood GM, Bellomo R, Bailey M, Lipcsey M, Pilcher D, Young P, Stow P, Santamaria J, Stachowski E, et al. Arterial carbon dioxide tension and outcome in patients admitted to the intensive care unit after cardiac arrest. Resuscitation. 2013;84(7):927-34.

66. Eastwood GM, Schneider AG, Suzuki S, Peck L, Young H, Tanaka A, Martensson J, Warrillow S, McGuinness S, Parke R, et al. Targeted therapeutic mild hypercapnia after cardiac arrest: a phase II multi-centre randomised controlled trial (the CCC trial). Resuscitation. 2016;104:83-90.

67. Curley G, Kavanagh BP, Laffey JG. Hypocapnia and the injured brain: more harm than benefit. Crit Care Med. 2010;38(5):1348-59.

68. Bouzat P, Suys T, Sala N, Oddo M. Effect of moderate hyperventilation and induced hypertension on cerebral tissue oxygenation after cardiac arrest and therapeutic hypothermia. Resuscitation. 2013;84(11):1540-5.

69. Helmerhorst HJ, Roos-Blom MJ, van Westerloo DJ, Abu-Hanna A, de Keizer $\mathrm{NF}$, de Jonge E. Associations of arterial carbon dioxide and arterial oxygen concentrations with hospital mortality after resuscitation from cardiac arrest. Crit Care. 2015:19:348

70. Beitler JR, Ghafouri TB, Jinadasa SP, Mueller A, Hsu L, Anderson RJ, Joshua J, Tyagi S, Malhotra A, Sell RE, et al. Favorable neurocognitive outcome with low tidal volume ventilation after cardiac arrest. Am J Respir Crit Care Med. 2017;195(9):1198-206.

71. Moskowitz A, Grossestreuer AV, Berg KM, Patel PV, Ganley S, Casasola Medrano M, Cocchi MN, Donnino MW, Center for Resuscitation S. The association between tidal volume and neurological outcome following inhospital cardiac arrest. Resuscitation. 2018;124:106-11.

72. Harmon MBA, van Meenen DMP, van der Veen A, Binnenkade JM, Dankiewicz J, Ebner F, Nielsen N, Pelosi P, Schultz MJ, Horn J, et al. Practice of mechanical ventilation in cardiac arrest patients and effects of targeted temperature management: a substudy of the targeted temperature management trial. Resuscitation. 2018;129:29-36.

73. Nolan JP, Soar J. Post resuscitation care--time for a care bundle? Resuscitation. 2008;76(2):161-2

74. Jakkula P, Reinikainen M, Hastbacka J, Pettila V, Loisa P, Karlsson S, LaruSompa R, Bendel S, Oksanen T, Birkelund T, et al. Targeting low- or highnormal carbon dioxide, oxygen, and mean arterial pressure after cardiac arrest and REsuscitation: study protocol for a randomized pilot trial. Trials. 2017;18(1):507.

Ready to submit your research? Choose BMC and benefit from:

- fast, convenient online submission

- thorough peer review by experienced researchers in your field

- rapid publication on acceptance

- support for research data, including large and complex data types

- gold Open Access which fosters wider collaboration and increased citations

- maximum visibility for your research: over $100 \mathrm{M}$ website views per year

At BMC, research is always in progress.

Learn more biomedcentral.com/submission 